Colonic perforation is a rare complication of laparoscopic inguinal hernioplasty with polypropylene mesh and it is usually due to mesh migration $[1,2]$. The presence of a colocutaneous fistula is a sign of high morbidity, and consideration should be given to treatment by endoscopy, although the usual treatment for this complication is open surgery. Fortunately, with advances in colonoscopy, therapeutic options have been developed. The most innovating is the use of endoclips [3].

We report a case of colocutaneous fistula due to mesh migration, that was treated with endoloops placed by colonoscopy.

A 50-year-old man had previously undergone a surgical procedure consisting of a left laparoscopic hernioplasty repair using a polypropylene mesh. At 5 months after surgery, the patient developed a hematoma on the surgical site, and 1 month later, he developed fever and secretion from an orifice that appeared on the left lower quadrant of the abdomen. A computed tomography (CT) scan showed a hypodense collection (18 H.U) of $6.2 \times 2.1 \times 2.1 \mathrm{~cm}$ and inflammatory process under the skin orifice, adjacent to the sigmoid colon.

Colonoscopy showed an orifice of $1 \mathrm{~cm}$ diameter in the sigmoid colon located $40 \mathrm{~cm}$ from the anal verge (Figure 1 ). Two endoloops (MAJ-254,HX-20L/Q/U-1; Olympus, Hamburg, Germany) were placed at the site of the inner orifice (Figure 2). To do this a cap was mounted on the tip of a forward-viewing endoscope to suck the mucosal lesion into the outlet of the cap and the endoloops were then placed. An improvement in symptoms and a decrease in the amount of secretion at the surgical wound was observed 1 month after the endoscopic procedure. At 6 months later, the patient was asymptomatic, with no secretion from the surgical wound and with total closure of the fistula. Therefore, as in this case, the use of endoloops could be an optional method for closing fistula tracts.

\title{
Endoloops as a Therapeutic Option in Colocutaneous Fistula Closure
}

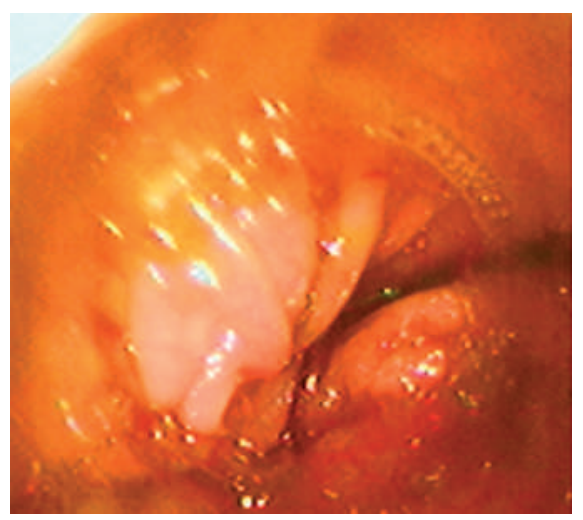

Figure 1 Endoscopic view showing the fistulous tract, located $40 \mathrm{~cm}$ from the anal margin.

\section{A. de Hoyos ${ }^{1}$, 0. Villegas ${ }^{1}$, J. M. Sánchez ${ }^{2}$,} M. A. Monroy ${ }^{1}$

${ }^{1}$ Department of Gastroenterology, Hospital Angeles del Pedregal, Mexico City, Mexico

2 Department of Radiology, Hospital Angeles del Pedregal, Mexico City, Mexico

\section{References}

${ }^{1}$ Bodenbach M, Bschleipfer T, Stoschek Met al. Intravesical migration of a polypropilene mesh implant 3 years after laparoscopic transperitoneal hernioplasty. Urologe A 2002; 41: 366 - 368

2 Benedetti M, Albertario S, Niebel Tet al. Intestinal perforation as a long-term complication of plug and mesh inguinal hernioplasty. Hernia 2005; 9: 93 - 95

${ }^{3}$ Yoshikane H, Hidano H, Sakakibara Aet al. Endoscopic repair by clipping of iatrogenic colonic perforation. Gastrointest Endosc 1997; 46: 464-466

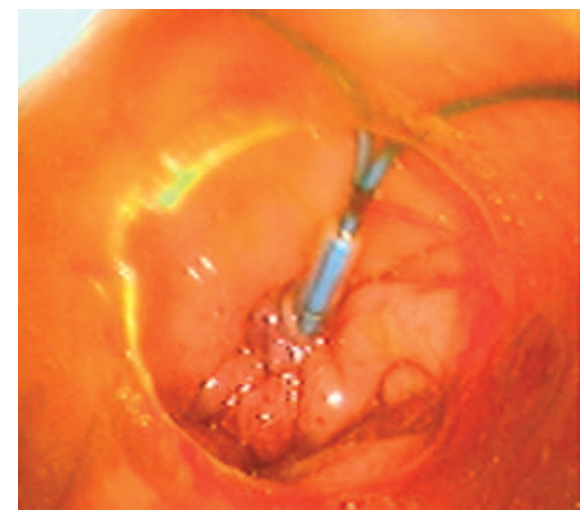

Figure 2 The fistulous tract is now closed with endoloops.

\section{Corresponding Author}

\section{A. de Hoyos, M.D.}

Department of Gastroenterology, Hospital Angeles del Pedregal Camino a Santa Teresa No 1055-119

Col. Héroes de Padierna Delegación Magdalena Contreras 10700 México City

México

E-mail: andehoyos@yahoo.com 